\title{
Predictors of future research interest among allied health professionals at an Australian regional tertiary hospital
}

\author{
T. Pain ${ }^{1,2}$, D. Lindsay ${ }^{2,3}$ \& M. Fernando ${ }^{2,4}$
}

\begin{abstract}
Introduction: Allied health professionals (AHPs) are core service providers in acute healthcare. AHPs' career trajectory may be via post-graduate education in clinical, management or research higher degrees. However, little is known of AHP post-graduate education and future research aspirations. This study calculates predictors of future research interest of AHPs at a regional Australian hospital.
\end{abstract}

Methods: A cross-sectional electronic survey was sent to all AHPs working for the Townsville Hospital Health Service from October 2014 until March 2015. The survey collected information about past, current and future education and research motivating factors. Data was analysed using SPSS (Version 24, IBM Corp, USA). Univariate and multivariate binomial logistic regression analyses were performed with future research interest as the outcome variable. Free-text responses were analysed with content analysis.

Results: Most AHPs (56\%) indicated they were interested in research in the future. The significant predictors of an increased likelihood of future research interest in our study cohort were prior master's or PhD qualification (OR: 4; 95\% CI: 1.1-15.6), fewer years since graduation (OR: 0.6, 95\% CI: 0.2-1.9), attending research education (OR: 2.9; 95\% CI: 1.3-6.6), having a research topic (OR: 4.9; 95\% CI: 1.9-13.9) and prior qualitative research experience (OR: 2.4; 95\% CI: 1.1-5.5).

Discussion: The predictive factors for future research quantifies allied health research interest for the first time. AHPs in clinical roles within hospital and health services have the potential to derive research questions from ground level clinical practice. Therefore, universities, hospital and health services and policymakers could exploit these predictive

\footnotetext{
Townsville Hospital and Health Service, Australia

College of Public Health, Medical and Veterinary Sciences, James Cook University, Australia

Menzies School of Health Research, Australia

College of Medicine and Dentistry, James Cook University, Australia
}

\section{Correspondence}

Dr. Tilley Pain

Townsville Hospital and Health Service

PO Box 670

Townsville, Queensland 4810

Australia

Tel: +61 744334154

Email: tilley.pain@health.qld.gov.au 
factors and strengthen their focus on supporting AHPs' research education at the level of developing research questions.

Conclusion: Predictors of future allied health research interest included having a research topic, having a master's or $\mathrm{PhD}$ qualification, fewer years since graduation and having prior research education or prior qualitative research experience.

Keywords: allied health; graduate education; research

\section{Introduction}

Allied health practitioners (AHPs) perform a range of healthcare roles, including primary and secondary prevention, health promotion and investigative, diagnostic, treatment and rehabilitative roles. AHPs in Queensland Health are classified under the health practitioner (Queensland Health) industrial agreement (No. 1), which encompasses more than 40 disciplines (Appendix). Most AHPs complete a 3 to 4-year undergraduate degree for registration into their discipline. Formal post-graduate training pathways to achieve recognition as a clinical specialist are available in some disciplines (e.g., Australian College of Physiotherapists) or through post-graduate vocational training schemes (e.g., clinical psychology or doctoral research degree). AHPs can also enrol in post-graduate management or research higher degrees (e.g., masters or PhD). This paper focuses on the latter group, and while it is not common for public health AHPs to pursue research with an interest in obtaining formal research training, the numbers are increasing.

Post-graduate education opportunities for AHPs are limited by lack of time and funding (Pain, Petersen, \& Fernando, 2018). One pathway for post-graduate education is formal research training via masters and $\mathrm{PhDs}$ or informal research education training offered by many health services (Harding, Stephens, et al., 2010). Research training programs within health services targeting motivated and interested clinicians can lead to tangible outputs, such as publications and increased enrolment of clinicians in research higher degrees (Harding, Shields, et al., 2016). However, to embed a culture of allied health research into healthcare services requires policy change followed by governance and organisational structure, research capability and advocacy by managers, dedicated research positions and strong links to universities and the individual attributes of clinicians (Slade et al., 2018).

It has previously been documented that AHP-led research can have clinical or economic impacts (Rahja et al., 2018; Standfield et al., 2016). The current healthcare climate has increasing burdens from complex chronic diseases and an aging population for which AHPs provide core healthcare roles (Elliott \& Leland, 2018; Quinton et al., 2015). Therefore, a more research enabled AHP workforce is needed, and for this to occur, we need to build and maintain the capability of AHPs to lead this research from within health services.

Understanding the research aspirations of future AHPs is important to identify who is interested, build a culture of research within hospital and health services and provide the appropriate resources and supports required to facilitate research. The aim of this 
research study was to provide insights into future research aspirations of AHPs at a regional tertiary teaching hospital and to determine the predictors associated with future research interest.

\section{Methods}

\section{Design}

A cross-sectional electronic survey was used to contact AHPs working for the Townsville Hospital Health Service via an email address list maintained by the organisation's workforce development officer. The survey link was initially sent in October 2014 and followed up by weekly email reminders until March 2015.

\section{Participants}

Any AHPs currently working for the Townsville Hospital Health Service were eligible for the study. The number of AHPs working for the Townsville Hospital Health Service in February 2015 was 614. To achieve a response rate greater than 40\%, 337 survey respondents were required.

\section{Data collection tool}

A SurveyMonkey (www.sureymonkey.com) questionnaire was used to disseminate the survey questions. The original survey (Pain, Plummer, et al., 2015) was developed by the researchers and modified for the follow up survey. The original survey consisted of 57 questions, including demographic (age, gender, years since graduation from basic degree, post-graduate qualifications, workplace characteristics) and research experience and support needs questions. The follow up survey consisted of 41 questions and was modified from the original to capture additional information regarding motivating factors for participating in research and future research interest. Responses were categorical (yes/no), 5-point Likert scale (strongly agree, agree, neither, disagree, strongly disagree) or free text.

\section{Data analysis}

Data from SurveyMonkey were exported to an Excel spreadsheet and modified into appropriate variables for transfer to Statistical Package for Social Sciences (SPSS) version 24 (IBM Corp, USA) for data analysis. Normality of continuous data was first checked using histograms, and data was reported as mean and standard deviation (SD). Categorical variables were reported as numbers and percentages (\%). Demographic data were stratified accordingly to various subgroups and presented using descriptive statistics.

Frequency analyses were initially performed to examine the characteristics of individuals who were and were not interested in research. As the primary outcome of interest is a binary variable (interest in future research: Yes/No), univariate binomial logistic regression analyses were initially used to predict future research interest based on various demographic and research-based questions. These predictors were chosen based 
on the researchers' belief they may influence the relevant outcome. Unadjusted odds ratios $(\mathrm{OR})$ and $95 \%$ confidence interval $(\mathrm{CI})$ values were obtained from the univariate analyses, with variables found to be significant at $p<0.05$ in the univariate analyses (along with confounding factors of sex and age) entered into a multivariate logistic regression to predict future research interest. The multivariate logistic regression was performed to examine which of the predictors from the initial univariate analysis were still significant when entered as a combination of factors. The final model, along with the adjusted ORs and 95\% CIs, was reported. Statistical significance was set at $p<0.05$ for all analyses.

Free-text responses are described quantitatively. A qualitative approach was not utilised given the limited free-text response data. The survey allowed free-text responses for two questions - the first about potential topic of research and the second about factors influencing participation in research. The data was analysed by one researcher (TP) and the frequency of key words was reported.

\section{Ethics}

This study was endorsed by the Townsville Hospital and Health Service Human Research Ethics Committee for endorsement as non-research (HREC/15/QTHS/23).

\section{Results}

The response rate was $37 \%(\mathrm{n}=234)$. The demographics of this workforce have been reported previously (Pain, Petersen, Fernando, 2018). Briefly, the AHPs in this cohort comprise a highly feminised workforce $(76 \%)$, working predominantly in acute care $(60 \%)$ and in clinical roles (60\%). Most participants were educated at the local university or another university within Queensland, and no participants identified as Indigenous (Table 1).

Approximately half (51.5\%) of the respondents reported having higher degrees, and $13.7 \%$ were currently enrolled. Those currently enrolled in a higher degree were completing their studies by course work $(7.5 \%)$, research $(3.1 \%)$ or both $(3.1 \%)$. The mode by which most preferred to receive this education was online $(51.6 \%)$ or distance $(29.0 \%)$ (Table 1$)$.

Fifty-six percent of respondents indicated they had an interest in future research. Univariate analysis indicated a greater likelihood of future research interest was associated with having a previous qualification of an honours or $\mathrm{PhD}$ degree, having fewer years since graduation, occupying a role where research is a core requirement, discipline and prior research education, having a research topic and prior qualitative or quantitative research experience (Table 2).

After adjusting for age and sex, the significant predictors of an increased likelihood of future research interest in our study cohort were fewer years since graduation, prior master's or PhD qualification, attending research education, having a research topic and prior qualitative research experience (Table 3). 


\section{PREDICTORS OF FUTURE RESEARCH INTEREST IN AHPS}

\section{Table 1}

Demographic Description of the Cohort

\begin{tabular}{|c|c|}
\hline Demographic & \\
\hline Response rate & $234 / 641$ (37\%) \\
\hline Females & $76 \%$ \\
\hline Age_-median (range) & $36(20-74)$ \\
\hline $\begin{array}{l}\text { Work setting } \\
\text { Hospital } \\
\text { Community } \\
\text { Outreach } \\
\text { Public health } \\
\text { Other }\end{array}$ & $\begin{array}{r}65 \% \\
16 \% \\
6 \% \\
2 \% \\
11 \%\end{array}$ \\
\hline $\begin{array}{l}\text { Work role } \\
\text { Clinical } \\
\text { Management } \\
\text { Both } \\
\end{array}$ & $\begin{array}{l}65 \% \\
16 \% \\
19 \%\end{array}$ \\
\hline $\begin{array}{l}\text { Education level } \\
\text { Bachelor } \\
\text { Honours } \\
\text { Post-graduate diploma } \\
\text { Post-graduate certificate } \\
\text { Masters } \\
\text { PhD }\end{array}$ & $\begin{aligned} 46.4 \% & (n=108) \\
14.1 \% & (n=33) \\
8.6 \% & (n=20) \\
5.6 \% & (n=13) \\
20.6 \% & (n=48) \\
2.6 \% & (n=6)\end{aligned}$ \\
\hline $\begin{array}{l}\text { Years since qualification } \\
\quad<10 \\
>10\end{array}$ & $\begin{array}{l}51.8 \%(n=121) \\
48.2 \%(n=113)\end{array}$ \\
\hline $\begin{array}{l}\text { Enrolled in higher education } \\
\text { No } \\
\text { Coursework } \\
\text { Research } \\
\text { Both }\end{array}$ & $\begin{aligned} 86.4 \% & (n=197) \\
7.5 \% & (n=17) \\
3.1 \% & (n=7) \\
3.1 \% & (n=7)\end{aligned}$ \\
\hline $\begin{array}{l}\text { Mode of learning } \\
\text { On campus } \\
\text { Block classes } \\
\text { Online } \\
\text { Distance }\end{array}$ & $\begin{aligned} 9.7 \% & (n=3) \\
6.5 \% & (n=2) \\
51.6 \% & (n=16) \\
29.0 \% & (n=9)\end{aligned}$ \\
\hline $\begin{array}{l}\text { Interest in future research? } \\
\text { Yes } \\
\text { No }\end{array}$ & $\begin{array}{r}123(56 \%) \\
97(44 \%)\end{array}$ \\
\hline
\end{tabular}


PREDICTORS OF FUTURE RESEARCH INTEREST IN AHPS

\section{Table 2}

Univariate Analysis of Predictors of Research Interest

\begin{tabular}{|c|c|c|c|c|c|}
\hline Variable & Level & $\begin{array}{c}\text { Interested } \\
(\mathrm{n}, \%)\end{array}$ & $\begin{array}{l}\text { Not Interested } \\
(n, \%)\end{array}$ & $\begin{array}{c}\text { Unadjusted } \\
\text { Odds Ratio } \\
\text { (95\% CI) }\end{array}$ & $p$-value \\
\hline \multirow[t]{2}{*}{ Sex } & Male & $35(67.3)$ & $17(32.7)$ & \multicolumn{2}{|c|}{ REF } \\
\hline & Female & $86(52.4)$ & 78 (47.6) & $0.5(0.3-1.1)$ & 0.06 \\
\hline \multirow[t]{3}{*}{ Age } & $<30$ years & $31(50.8)$ & $30(49.2)$ & \multicolumn{2}{|c|}{ REF } \\
\hline & $31-40$ years & $40(60.6)$ & $26(39.4)$ & $1.6(0.8-3.2)$ & 0.20 \\
\hline & $41+$ years & $38(52.1)$ & $35(47.9)$ & $1.1(0.6-2.2)$ & 0.74 \\
\hline \multirow[t]{4}{*}{ Qualifications } & Grad dip/cert & $11(33.3)$ & $22(67.7)$ & \multicolumn{2}{|c|}{ REF } \\
\hline & Bachelor & 48 (48.5) & $51(51.5)$ & $1.9(0.8-4.4)$ & 0.13 \\
\hline & Honours & $22(66.7)$ & $11(33.3)$ & $4.0(1.5-11.5)$ & 0.008 \\
\hline & PhD/masters & 41 (75.9) & $13(24.1)$ & $6.3(2.5-17)$ & $<0.001$ \\
\hline \multirow{3}{*}{$\begin{array}{l}\text { Years since } \\
\text { graduation }\end{array}$} & $<5$ & $35(61.4)$ & $22(38.6)$ & \multicolumn{2}{|c|}{ REF } \\
\hline & $6-10$ & $34(63)$ & $20(37)$ & $1.1(0.5-2.3)$ & 0.86 \\
\hline & $11+$ & $49(48.5)$ & $52(51.5)$ & $0.6(0.3-1.1)$ & 0.02 \\
\hline \multirow[t]{4}{*}{ Role at work } & Clinical only & $78(55.3)$ & $63(44.7)$ & \multicolumn{2}{|c|}{ REF } \\
\hline & Clinical/management mix & $21(61.8)$ & $13(38.2)$ & $1.3(0.9-1.7)$ & 0.50 \\
\hline & Management only & $9(60)$ & $6(40)$ & $1.2(0.4-3.8)$ & 0.73 \\
\hline & Other & $15(50)$ & $15(50)$ & $0.8(0.4-1.8)$ & 0.60 \\
\hline \multirow[t]{3}{*}{ Team } & Multidisciplinary & $83(56.1)$ & $65(43.9)$ & \multicolumn{2}{|c|}{ REF } \\
\hline & Single discipline & $32(64)$ & $18(36)$ & $1.4(0.7-2.7)$ & 0.33 \\
\hline & Mix & $7(35)$ & $13(65)$ & $0.4(0.2-1.1)$ & 0.08 \\
\hline \multirow[t]{3}{*}{ Research in role } & No & $38(47.5)$ & $42(52.5)$ & \multicolumn{2}{|c|}{ REF } \\
\hline & Yes & $65(64.4)$ & 36 (35.6) & $2.0(1.1-3.7)$ & 0.02 \\
\hline & Don't know & $18(48.6)$ & 19 (51.4) & $1.0(0.5-2.3)$ & 0.90 \\
\hline \multirow[t]{3}{*}{ Work setting } & Hospital & $84(59.6)$ & $57(40.4)$ & \multicolumn{2}{|c|}{ REF } \\
\hline & Community & $19(55.9)$ & $15(44.1)$ & $0.9(0.4-1.9)$ & 0.69 \\
\hline & Other & $17(42.5)$ & $23(57.5)$ & $0.5(0.2-1.0)$ & 0.06 \\
\hline \multirow[t]{6}{*}{ Discipline } & OT & $20(40.8)$ & $29(59.2)$ & \multicolumn{2}{|c|}{ REF } \\
\hline & PT & $23(67.6)$ & $11(32.4)$ & $3.0(1.2-7.8)$ & 0.02 \\
\hline & Dietitian & $11(61.1)$ & $7(38.9)$ & $2.3(0.8-7.2)$ & 0.14 \\
\hline & Pharmacist & $8(61.5)$ & $5(38.5)$ & $2.3(0.7-8.7)$ & 0.19 \\
\hline & Psychologist & $9(90)$ & $1(10)$ & $13.0(2.2-250.5)$ & 0.02 \\
\hline & Other & 52 (54.2) & 44 (45.8) & $1.7(0.6-3.5)$ & 0.13 \\
\hline \multirow{2}{*}{$\begin{array}{l}\text { Attendance at } \\
\text { journal clubs }\end{array}$} & No & 52 (49.5) & $53(50.5)$ & \multicolumn{2}{|c|}{ REF } \\
\hline & Yes & 69 (62.2) & $42(37.8)$ & $1.7(1-2.9)$ & 0.06 \\
\hline
\end{tabular}


PREDICTORS OF FUTURE RESEARCH INTEREST IN AHPS

\section{Table 2}

Univariate Analysis of Predictors of Research Interest (contd.)

\begin{tabular}{|c|c|c|c|c|c|}
\hline Variable & Level & $\begin{array}{l}\text { Interested } \\
(\mathrm{n}, \%)\end{array}$ & $\begin{array}{l}\text { Not Interested } \\
\qquad(\mathrm{n}, \%)\end{array}$ & $\begin{array}{c}\text { Unadjusted } \\
\text { Odds Ratio } \\
(95 \% \mathrm{Cl})\end{array}$ & $p$-value \\
\hline Research & No & $60(44.4)$ & 75 (55.6) & \multicolumn{2}{|c|}{ REF } \\
\hline education & Yes & $63(75)$ & $21(25)$ & $3.8(2.1-6.9)$ & $<0.001$ \\
\hline Current topic & No & $70(45.2)$ & $85(54.8)$ & \multicolumn{2}{|c|}{ REF } \\
\hline & Yes & $53(85.5)$ & $9(14.5)$ & $7.2(3.4-16.4)$ & $<0.001$ \\
\hline Qual experience & No & $57(49.1)$ & $59(50.9)$ & \multicolumn{2}{|c|}{ REF } \\
\hline & Yes & $57(66.3)$ & $29(33.7)$ & $2.0(1.1-3.6)$ & 0.02 \\
\hline Quant experience & No & $43(43.4)$ & $56(56.6)$ & \multicolumn{2}{|c|}{ REF } \\
\hline & Yes & $72(69.2)$ & $32(30.8)$ & $2.9(1.7-5.3)$ & $<0.001$ \\
\hline
\end{tabular}

Note: No values were calculated for REF as these categorical levels were used as the reference for analysis of each variable.

\section{Table 3}

Multivariate Analysis of Predictors of Research Interest

\begin{tabular}{|c|c|c|c|}
\hline Variable & Level & $\begin{array}{c}\text { Unadjusted Odds } \\
\text { Ratio } \\
(95 \% \mathrm{Cl})\end{array}$ & $p$-value \\
\hline \multirow[t]{3}{*}{ Age } & $<30$ years & \multicolumn{2}{|c|}{ REF } \\
\hline & $31-40$ years & $2.2(0.7-7.5)$ & 0.21 \\
\hline & $41+$ years & $1.7(0.5-6.8)$ & 0.44 \\
\hline \multirow[t]{2}{*}{ Gender } & Male & \multicolumn{2}{|c|}{ REF } \\
\hline & Female & $0.5(0.2-1.3)$ & 0.17 \\
\hline \multirow[t]{3}{*}{ Years since graduating } & $<5$ years & \multicolumn{2}{|c|}{ REF } \\
\hline & $6-10$ years & $0.6(0.2-1.9)$ & 0.42 \\
\hline & $11+$ years & $0.2(0.1-0.8)$ & 0.02 \\
\hline \multirow[t]{4}{*}{ Qualifications } & Grad dip/cert & \multicolumn{2}{|c|}{ REF } \\
\hline & Bachelor & $0.9(0.3-3)$ & 0.95 \\
\hline & Honours & $1.8(0.5-7.4)$ & 0.40 \\
\hline & Masters/PhD & $4.0(1.1-15.6)$ & 0.04 \\
\hline \multirow[t]{2}{*}{ Attended research education } & No & \multicolumn{2}{|c|}{ REF } \\
\hline & Yes & $2.9(1.3-6.6)$ & .01 \\
\hline \multirow[t]{2}{*}{ Current topic chosen } & No & \multicolumn{2}{|c|}{ REF } \\
\hline & Yes & 4.9 (1.9-13.9) & 0.001 \\
\hline \multirow[t]{2}{*}{ Qualitative research experience } & No & \multicolumn{2}{|c|}{ REF } \\
\hline & Yes & $2.4(1.1-5.5)$ & 0.03 \\
\hline
\end{tabular}

Note: No values were calculated for REF as these categorical levels were used as the reference for analysis of each variable. 


\section{Free-text responses}

The survey provided an opportunity for participants to nominate what topic of research they may perform if given capacity. Thirty-six free-text responses were given, of which five did not state a topic. Diverse topics representing various disciplines, diseases and patient populations were stated (Table 4). Participants were also asked to nominate factors that would influence them to get involved in research. The overwhelming influencing factor was time. To a much lesser extent, funding was also cited as an influencing factor (Table 4).

\section{Table 4}

Frequency of Free-Text Responses to Open-Ended Questions

\begin{tabular}{l|c}
\hline Topic of research interest & Frequency (out of 36) \\
\hline Mental health & 8 \\
\hline Rural/remote health & 4 \\
\hline Aged/elderly care & 4 \\
\hline Indigenous/Aboriginal health & 3 \\
\hline Rehabilitation & 3 \\
\hline Dementia & 2 \\
\hline Diabetes & 2 \\
\hline
\end{tabular}

What initiatives would encourage you to be more involved in research?

\begin{tabular}{l|l}
\hline Time & 8 \\
\hline Funding/financial incentives & 3 \\
\hline Less clinical work/more staff & 3 \\
\hline
\end{tabular}

\section{Discussion}

There is limited evidence indicating which factors predict future research interest amongst AHPs in Australia (Finch et al., 2013). On the other hand, many studies describe enablers and barriers to research at individual, team, organisational and external levels (Alison et al., 2017; Barratt \& Fulop, 2016; Borkowski et al., 2016; Harvey et al., 2016; Holden et al., 2012; Pain, Petersen, \& Fernando, 2018; Wenke et al., 2018). This study demonstrates factors that predict future research interest include having a research question, having an honours, master's or $\mathrm{PhD}$ degree and prior exposure to research education. Overall, our results imply an opportunity for universities, hospital and health services and policymakers to strengthen their focus on supporting AHPs' future research interests and education.

Research education, if targeted to motivated clinicians, can lead to tangible outputs in clinical settings (Harding, Stephens, et al., 2010). The essential first step in becoming a clinician researcher is the research debut (Harvey et al., 2016), whether the debut is via tertiary education or participation in some research or quality improvement activity. Therefore, investment in research education is likely to increase research 
capacity and ultimately health outcomes (Ozdemir et al., 2015). The judicious use of research outcomes and evaluation of best evidence and practice in healthcare is integrally linked to the research capacity and capability of the workforce, suggesting a strong collaboration between academic and healthcare partners may enhance the use of research in clinical practice (Whitworth et al., 2012). Therefore, health services can potentially harness the individual attributes of clinicians, such as their research skills and capabilities, motivation and participation in research teams to embed research into practice (Slade et al., 2018)

Many of the described predictive factors are not surprising. The relationship between factors such as attendance at research education, having a current topic chosen already and having higher university qualifications with an increased interest in future research imply a desire to conduct research. Having a current topic chosen was, from a statistical perspective, the strongest predictor of future research interest, highlighting that for research to grow amongst AHPs, choosing a topic of interest for research is crucial. Importantly, the current study suggests allied health research activity may be increased by providing research education on how to convert a clinical question into a research question, by providing research education within hospital and health services and by encouraging post-graduate research courses amongst AHPs. As AHPs are often at the ground level of clinical practice, their research topics may arise from interactions they have with patients within the healthcare system. This suggests a potential dependency of clinician driven research on prior exposure to research, which enables AHPs to recognise research questions at the coalface of clinical practice. While research is not the core function of AHP clinical roles, research interested and motivated clinicians need the support of the health system to build their capacity to conduct research alongside their care delivery functions. Therefore, it is vital that AHPs are assisted in the process of taking clinical and administrative experiences and the questions that arise from these to formulate proper research topics and drive the research process.

Exposure to research education was also an important predictor. This may occur in the form of formal post-graduate education or internal (in-service) education sessions. This study shows approximately half of the AHPs at a regional tertiary hospital have, or are doing, post-graduate study. The preferred mode of learning was online or distance education, although course work was preferred predominantly in specialist clinical areas, with a small but increasing proportion of AHPs pursuing post-graduate research-based study. This research suggests AHPs have a high commitment to ongoing education, as approximately $50 \%$ of AHP participants indicated they have post-graduate education. Previous reviews of allied health education focused on entry-level post-graduates (Queensland Health, 2007), with limited evidence on post-graduate education in clinical, management or research fields. Continuous professional development allows AHPs to transition from novice to expert over time and to maintain recency of practice, so they perform at an acceptable level to meet patient needs and are versed in the growing evidence base supporting various interventions. However, the process of gaining the skills demanded means they may become automated in their everyday tasks as they adapt to performance demands of the health service. Therefore, experts 
seek out training that exceeds their current level of performance (Faucher, 2016). The high proportion of AHPs with post-graduate clinical education and the preference for online education fits with the predominantly clinical role of AHPs at this facility. An incentive to enrol in post-graduate education via a study and research assistance scheme is active in Townsville Hospital Health Service but requires management support of the level of benefit that accrues to the health service to ascertain the monetary value of the incentive. Satisfaction was the same for face-to-face versus online education for rural allied health professionals but had no impact on workforce retention (Berndt et al., 2017).

Individuals who were longer than 10 years from their graduation were found to have less interest in future research. This suggests individuals who have been in the workforce longer may be more engaged in clinical activities and not perceive research as an important aspect of their role. Those with fewer years since their graduation have a greater interest in research, which may indicate that research is becoming more important for new graduate AHPs. Our research suggests exposing AHPs to research education "demystifies" research and opens a pathway to investigate their clinical question. Locally, the organisation has invested in building a research culture through a dedicated staff research position, education and research infrastructure.

AHPs participate in internal management and leadership programs within health services. Changes in health governance structures over the last 10-20 years has meant allied health has come out from under the umbrella of medicine (Boyce, 2001). However, AHPs are rarely the subject of policy debates, and there is concern their contribution to care is often hidden, overlooked or potentially undervalued (Dorning $\&$ Bardsley, 2014). Focusing on building AHP research and leadership capacity may tap the potential of AHPs in the Australian healthcare system (Philip, 2015).

The main limitation of our study was the cross-sectional design. Due to the crosssectional nature of this study, a cause and effect relationship could not be ascertained between the predictors assessed in this study and future research interest. Future studies should aim to track AHPs over time to examine how interaction with research activities and/or education influences this research interest. Further, due to the cross-sectional design, it is difficult to ascertain whether responses are indicative of actual outcomes, as the external validity of our study is limited and the results should be considered for the population studied. While this study was able to provide some significant predictors for future research interest, the lack of in-depth qualitative information beyond freetext responses means this study did not investigate in greater detail why participants answered the way they did. Future research could explore this topic area using a more in-depth qualitative approach in order to further understand the aspects underlying the future research interests of AHPs. It is also noted that the main survey tool used in this study has no prior validation, which limits the validity of the results and their application in a larger context. 
The strengths of our study were a conservative statistical approach and the large number of people surveyed. Our study reports on future research interests, and whether these predictors have any association to future research output is uncertain and should be the focus of future work. However, this study is of potential benefit to health services, tertiary education institutions and policymakers in their decision making on postgraduate education, research career pathways and research supports.

\section{Conclusion}

The predictors of future research interests amongst AHPs working in a regional hospital and health service include having a research question, having an honours or a higher research degree and prior exposure to research education. Future research interest was also stronger among people who recently graduated with an undergraduate degree. These factors should be considered by tertiary education institutions, hospital and health services and policymakers in the planning of research education and support for future AHPs to increase allied health research capacity in Australia.

\section{Funding and conflict of interest statement}

The authors have no competing interests. The Townsville Hospital and Health Service Study, Education, and Research Trust Account provided funding for this research.

\section{References}

Alison, J. A., Zafiropoulos, B., \& Heard, R. (2017). Key factors influencing allied health research capacity in a large Australian metropolitan health district. Journal of Multidisciplinary Healthcare, 10, 277-291. https://doi.org/10.2147/JMDH. S142009

Barratt, H., \& Fulop, N. J. (2016). Building capacity to use and undertake research in health organisations: A survey of training needs and priorities among staff. $B M J$ Open, 6(12), e012557. https://doi.org/10.1136/bmjopen-2016-012557

Berndt, A., Murray, C. M., Kennedy, K., Stanley, M. J., \& Gilbert-Hunt, S. (2017).

Effectiveness of distance learning strategies for continuing professional development (CPD) for rural allied health practitioners: A systematic review. BMC Medical Education, 17(1), Article 117. https://doi.org/10.1186/s12909-017-0949-5

Borkowski, D., McKinstry, C., Cotchett, M., Williams, C., \& Haines, T. (2016). Research culture in allied health: A systematic review. Australian Journal of Primary Health, 22(4), 294-303. https://doi.org/10.1071/py15122

Boyce, R. A. (2001). Organisational governance structures in allied health services: A decade of change. Australian Health Review, 24(1), 22-36. https://doi. org/10.1071/ah010022 
Dorning, H., \& Bardsley, M. (2014). QualityWatch: Focus on allied health professionals_Can we measure quality of care? The Health Foundation and the Nuffield Trust. https://www.health.org.uk/publications/qualitywatch-focus-onallied-health-professionals

Elliott, S., \& Leland, N. E. (2018). Occupational therapy fall prevention interventions for community-dwelling older adults: A systematic review. American Journal of Occupational Therapy, 72(4), 7204190040p1-7204190041p11. https:// doi.org/10.5014/ajot.2018.030494

Faucher, C. (2016). Developing healthcare practitioners' professional expertise through effective continuing education: Commentary. The Internet Journal of Allied Health Sciences and Practice, 14(4), Article 7. https://nsuworks.nova.edu/cgi/ viewcontent.cgi? article $=1593 \&$ context $=$ ijahsp

Finch, E., Cornwall, P., Ward, E., \& McPhail, S. (2013). Factors influencing research engagement: Research interest, confidence and experience in an Australian speechlanguage pathology workforce. BMC Health Services Research, 13, Article 144. https://doi.org/10.1186/1472-6963-13-144

Harding, K., Stephens, D., Taylor, N., Chu, E., \& Wilby, A. (2010). Development and evaluation of an allied health research training scheme. Journal of Allied Health, 39(4), e143-148.

Harding, K. E., Shields, N., Whiteside, M., \& Taylor, N. F. (2016). "A great first step into research": Stepping into research is an effective and sustainable model for research training in clinical settings-A report of 6-year outcomes. Journal of Allied Health, 45(3), 176-182.

Harvey, D., Plummer, D., Neilsen, I., Adams, R., \& Pain, T. (2016). Becoming a clinician-researcher in allied health. Australian Health Review, 40(5), 562-569. https://doi.org/10.1071/AH15174

Holden, L., Pager, S., Golenko, X., \& Ware, R. (2012). Validation of the research capacity and culture (RCC) tool: Measuring RCC at individual, team and organisation levels. Australian Journal of Primary Health, 18, 62-67. https://doi. org/10.1071/PY10081

Ozdemir, B. A., Karthikesalingam, A., Sinha, S., Poloniecki, J. D., Hinchliffe, R. J., Thompson, M. M., Gower, J. D., Boaz, A., \& Holt, P. J. (2015). Research activity and the association with mortality. PLoS One, 10(2), e0118253. https://doi. org/10.1371/journal.pone.0118253

Pain, T., Petersen, M., \& Fernando, M. (2018). Building allied health research capacity at a regional Australian hospital: A follow-up study. Internet Journal of Allied Health Sciences \& Practice, 16(4), Article 8. https://nsuworks.nova.edu/cgi/ viewcontent.cgi? article $=1813 \&$ context $=$ ijahsp

Pain, T., Plummer, D., Pighills, A., \& Harvey, D. (2015). Comparison of research experience and support needs of rural versus regional allied health professionals. Australian Journal of Rural Health, 23, 277-285. https://doi.org/10.1111/ ajr. 12234 
Philip, K. (2015). Allied health: Untapped potential in the Australian health system. Australian Health Review, 39(3), 244-247. https://doi.org/10.1071/AH14194

Queensland Health. (2007). Ministerial taskforce on clinical education and training. Final report_March 2007. https://www.health.qld.gov.au/_data/assets/pdf_ file/0033/147399/mt-clinedtrain.pdf

Quinton, T. R., Lazzarini, P. A., Boyle, F. M., Russell, A. W., \& Armstrong, D. G. (2015). How do Australian podiatrists manage patients with diabetes? The Australian diabetic foot management survey. Journal of Foot and Ankle Research, 8 , 16. https://doi.org/10.1186/s13047-015-0072-y

Rahja, M., Comans, T., Clemson, L., Crotty, M., \& Laver, K. (2018). Economic evaluations of occupational therapy approaches for people with cognitive and/ or functional decline: A systematic review. Health Social Care in the Community. https://doi.org/10.1111/hsc.12553

Slade, S. C., Philip, K., \& Morris, M. E. (2018). Frameworks for embedding a research culture in allied health practice: A rapid review. Health Research Policy System, 16(1), Article 29. https://doi.org/10.1186/s12961-018-0304-2

Standfield, L., Comans, T., Raymer, M., O'Leary, S., \& Moretto, N. (2016). The efficiency of increasing the capacity of physiotherapy screening clinics or traditional medical services to address unmet demand in orthopaedic outpatients: A practical applicaiton of discrete event simulation with dynamic queuing. Applied Health Economics and Health Policy, 14(4), 479-491. https://doi.org/10.1007/ s40258-016-0246-1

Wenke, R. J., Tynan, A., Scott, A., \& Mickan, S. (2018). Effects and mechanisms of an allied health research position in a Queensland regional and rural health service: A descriptive case study. Australian Health Review, 42(6), 667-675. https://doi. org/10.1071/ah17086

Whitworth, A., Haining, S., \& Stringer, H. (2012). Enhancing research capacity across healthcare and higher education sectors: Development and evaluation of an integrated model. BMC Health Services Research, 12(1), Article 287. https://doi. org/10.1186/1472-6963-12-287 


\section{Appendix}

\section{List of Eligible Disciplines and Professions}

(a) Anaesthetic technicians

(b) Art therapists

(c) Audiologists

(d) Biomedical engineers and technicians

(e) Breast imaging radiographers

(f) Cardiac perfusionists

(g) Chemists and/or radiochemists

(h) Child guidance therapists

(i) Child therapists

(j) Clinical measurement scientists and technicians

(k) Dental officers

(l) Dental prosthetists

(m) Dental technicians

(n) Dental therapists

(o) Dietitians/nutritionists

(p) Environmental health officers

(q) Epidemiologists

(r) Exercise physiologists

(s) Forensic scientists and technicians

(t) Genetic counsellors

(u) Health promotion officers

(v) Leisure therapists

(w) Medical illustrators

(x) Medical laboratory scientists and technicians

(y) Music therapists

(z) Neurophysiologists

(aa) Neuropsychologists

(bb) Nuclear medicine technologists

(cc) Nutritionists

(dd) Occupational therapists

(ee) Oral health therapists

(ff) Orthoptists

(gg) Orthotists, prosthetists and technicians

(hh) Patient safety officers

(ii) Pharmacists and technicians

(jj) Physicists, including radiation oncology medical physicists, nuclear medical physicists, radiology medical physicists and health physicists 
PREDICTORS OF FUTURE RESEARCH INTEREST IN AHPS

(kk) Physiotherapists

(ll) Podiatrists

(mm) Psychologists, including clinical and neuropsychologists

(nn) Public health officers

(oo) Radiation therapists

(pp) Radiographers/medical imaging technologists

(qq) Rehabilitation engineers and technicians

(rr) Researchers, clinical trial coordinators and data collection officers; scientists environmental health

(ss) Social work associates

(tt) Social workers

(uu) Sonographers

(vv) Speech pathologists

(ww) Welfare officers

Source: Queensland Industrial Relations Commission. (2016). Health Practitioners and Dental Officers (Queensland Health) Certified Agreement (No. 2), 2016, p. 28 